


\section{PROBLEMATICA AMBIENTAL EN HONDURAS: RESPUESTAS DESDE EL DERECHO}

Por Dr. Mario Vallejo Larios, Ph.D. en la Universidad de Alicante, España, Abogado en la Universidad Nacional Autónoma de Honduras. Profesor de la Universidad Tecnologica de Honduras. E-Mail:m.vallejo@usa.net

\section{Resumen}

La situación ambiental a nivel global es sumamente preocupante y Honduras no escapa a esa realidad. En el campo del Derecho Honduras ha aprobado aproximadamente 50 tratados internacionales y más de 100 leyes secundarias sobre ambiente o recursos naturales, sumando una cantidad indeterminada de normas reglamentarias, lo que se presenta como un escenario jurídico adecuado. Sin embargo hay inconvenientes: la cantidad y dispersión de normas legales, un marco administrativo y judicial débil, y profesionales con poco conocimiento sobre la temática ambiental puede ser una fórmula para la ineficacia, anulando los impactos positivos para el ambiente que se pretende con esa normativa especializada.

Los juristas ambientalistas pueden hacer la dife-rencia, pero se requiere que la academia asuma un rol acorde con los retos del nuevo milenio, formando profesionales capaces de interpretar las disposiciones legales ambientales, aunando una base técnica a su formación jurídica, porque el Derecho Ambiental trasciende lo jurídico.

Palabras clave: Derecho, Ambiente, Educación Ambiental; Universidad

\section{Abstract}

The overall environmental situation is extremely worrying and Honduras is not exception to this reality. Honduras has approved about 50 international treaties and over 100 secondary laws on environmental and natural resources, adding any number of regulations, which are presented as an appropriate legal scenario. However, there are some drawbacks: the amount and dispersion of laws, weak administrative and judicial framework, and professionals with little knowledge about environmental issues can be a formula for inefficiency, negating the positive impacts on the environment that is intended by this specialized legislation.

Environmentalist lawyers can make a difference, but it requires that the academic world assumes a commensurate role with the challenges of the new millennium, training professionals able to interpret environmental laws, adding a technical foundation to their legal training qualifications, because Environmental Law transcends the legal field.

Keywords: Law, environment, environmental education, University 


\section{INTRODUCCIÓN}

"En un mundo con una población creciente, una desigualdad flagrante y una base ambiental precaria, es imperativo que los Gobiernos y toda la sociedad colaboren para equilibrar las vertientes económica, social y ambiental del desarrollo sostenible".

Ban Ki-Moon, Secretario General de la ONU

\section{A. Generalidades}

Estudios recientes concluyen que en los últimos 50 años, la población mundial, en especial la clase alta, y un poco menos la clase media, han duplicado sus niveles de consumo, al tiempo que entre mil y dos mil millones de personas aspiran a formar parte de la clase consumidora mundial y se agregan a los miles de millones que ya padecen hambre.

Como expresa Sir Edmund Hillary, primer hombre en conquistar el Monte Everest: "Los golosos del mundo literalmente le quitan la comida de la boca a los más pobres" (Ecología 2000). Lo que vale para las personas, vale también para los países. Los más desarrollados esquilman los recursos naturales de los menos desarrollados, que aprovechan para su beneficio exclusivo y los despilfarran a su antojo, amenazando con dejar los suelos convertidos en desiertos, sin agua, en vertederos de residuos tóxicos y peligrosos, o en situaciones igualmente apocalípticas.

Lo anterior es particularmente grave con el aumento de la población mundial. "La población humana alcanzó los 7 mil millones de personas en 2011 y se espera que llegue a los 10 mil millones para 2100" (PNUMA 2012).

El planeta no puede mantener tales incrementos en la demanda de recursos sin que esto tenga graves consecuencias tanto para las personas como para los ecosistemas ${ }^{1}$. "Las crecientes tensiones sobre los ecosistemas y la presión sobre los recursos vienen acompañados por problemas socio-económicos cada vez mayores: la implosión de instrumentos financieros especulativos que ha conducido a la crisis económica, las crecientes desigualdad y vulnerabilidad sociales y la inseguridad laboral. Con todo ello, resulta difícil no concluir que la economía ha dejado de trabajar a favor de las personas y del planeta" (Worldwatch 2012).

Los patrones de la globalización (comercio, finanzas, tecnología y comunicación) han propiciado una gran presión sobre los recursos naturales, alterando el medio ambiente. La gene-

1 Por ecosistema se entiende: "Una unidad formada por el conjunto de elementos vegetales y animales que conviven en un medio fisico concreto, p.e. una montaña, un rio, un lago, etc”. (Editorial Cientifíca) 
ración de energía a partir de biomasa (árboles, maíz, caña de azúcar o palmas) ha incrementado a ritmo acelerado causando escasez de granos básicos para la alimentación y cambiando de uso extensas áreas de suelo.

“En los primeros años del siglo XXI, el biodiesel se volvió más accesible, con una producción que crece alrededor del $60 \%$ por año, y que alcanzó cerca de 13 millones de toneladas equivalentes de petróleo en 2009. Sin embargo, información reciente ha despertado inquietudes por las directas consecuencias ambientales y sociales de la producción a gran escala de biocombustibles. Estas incluyen, entre otras, a la deforestación y la conversión de la tierra, la introducción de especies potencialmente invasoras, la sobreexplotación del agua, los efectos en el mercado global de alimentos, y la compra o arrendamiento de tierras por parte de inversionistas extranjeros para producir alimento y biocombustibles, generalmente en países en vías de desarrollo y a veces en países semiáridos" (PNUMA Ob cit).

Una situación como la planteada exige de normas que en un sentido amplio de justicia regulen de forma equitativa las relaciones humanas. El Derecho como ciencia tiene por objeto el estudio, la interpretación, integración y sistematización de un ordenamiento jurídico para su justa aplicación. Sin embargo, las disciplinas jurídicas tradicionales no alcanzan para regular la materia ambiental, que por su naturaleza es global, multidiciplinaria y con un sustrato metajurídico. Se hace evidente la necesidad de encontrar las medidas en que el Derecho puede contribuir a la solución de los problemas medioambientales, cuya magnitud a nivel global se percibe enorme por la cobertura mediática, pero que empiezan en el ámbito local; eso es Derecho Ambiental. "Se debe insistir sobre la importancia de la adopción efectiva de instrumentos jurídicos apropiados en el plano internacional y nacional, con vistas a la protección del medio natural y del ambiente. El Derecho Ambiental no es un simple apéndice de las políticas ambientales, es el medio privilegiado para toda política a favor del ambiente" (Mateo 1991).

\section{B. Alcances del presente artículo}

Con este artículo se pretende introducir a los profesionales y estudiantes de Derecho, a la novísima y compleja ciencia del Derecho Ambiental. Para lo anterior es indispensable conocer cuál es el estado actual del ambiente y las situaciones que han generado la preocupación mundial por una materia que hasta hace pocos años sólo era conocida por un reducido número de científicos y técnicos de las ciencias biológicas y sociales, y cuál es el papel del Derecho para contribuir con las soluciones.

El estudio, que empieza con una panorámica a la situación ambiental global, tiene su mayor relevancia en los capítulos que plantean la situación ambiental en Honduras, con sus particu- 
lares problemas y sus propias medidas de solución por medio del Derecho.

La expectativa es que los juristas encuentren un incentivo para incursionar en el estudio del Derecho Ambiental y sus diferentes avenidas. Esto, además de una oportunidad profesional, representa una buena forma de contribuir para que las soluciones por el Derecho ayuden a que haya equidad intergeneracional, porque las futuras generaciones tienen derecho a gozar de los mismos beneficios del ambiente y los recursos naturales que hemos tenido los actuales pobladores del planeta tal como lo señala un proverbio indio (autor desconocido): "La tierra no es una herencia que recibimos de nuestros padres, sino un préstamo de nuestros hijos".

\section{C. ¿ ¿Por qué es importante el tema ambiental en la Revista de Derecho?}

El estudio del Derecho Ambiental es una oportunidad y una necesidad para los estudiantes y profesionales del Derecho. En la medida que la Revista de Derecho llegue a lectores interesados en esta temática puede incidir para los juristas, sean estos procuradores, jueces, fiscales, consultores, etc., encuentren nuevas oportunidades profesionales en un ámbito diferente al que normalmente se estudia en la academia y al mismo tiempo, que la Universidad Nacional Autónoma de Honduras y otras instituciones de educación superior que ofrecen carreras vinculadas al ambiente, puedan considerar la posibilidad de incluir asignaturas relacionadas con el Derecho Ambiental, tanto el que aplica de forma general, como el que es particularmente importante de acuerdo a la situación del país, es especial para el estudio de la legislación aplicable a los temas forestales, de suelos, aguas, turismo e indígenas, entre otras.

\section{CAPÍTULO I CONTEXTO AMBIENTAL MUNDIAL}

\section{A. Ambiente y Derecho: ¿ matrimonio por conveniencia?}

El interés del hombre por el ambiente y la problemática que lo circunda no es reciente, sino que se remonta muchos siglos atrás. En las culturas antiguas de todos los continentes abundan los ejemplos de la preocupación humana por los recursos naturales y su propio entorno, misma que se refleja en hechos que establecen vínculos tempranos entre Ambiente y Derecho. La importancia de los árboles obligó a la introducción temprana de regulaciones para su manejo que se encontraban en el Código de Hammurabi, que rigió en Mesopotamia alrededor de 1700 a.C. En la antigua Roma, los recursos naturales como el suelo, el agua, los yacimientos minerales, la flora y la fauna y los recursos escénicos fueron considerados, "res communis", es decir, cosas de la comunidad, que pueden ser empleadas por todos, salvo en cuanto hubieren determinado derechos particulares sobre pequeñas porciones individuales. 
“El emperador Julio César expidió una norma ambiental que prohibía la circulación de carruajes en algunos barrios de Roma y Pompeya, en razón al ruido que emitían y a la producción de excrementos que contaminaban dichas ciudades y Eduardo I de Inglaterra reglamentó en 1273 la emisión de humos; en el fuero juzgo y la ley de las siete partidas se consideró los ríos y caminos como bienes comunes en la época de la colonia (Perea p.e.)".

En la mitología de diferentes culturas de la antigüedad se divinizó a los principales elementos asociados al ambiente como el agua, la tierra, el viento, los bosques y en general, las fuerzas de la naturaleza; "pero es en la segunda mitad del pasado siglo cuando se le dio un especial énfasis al tema ambiental, para asegurar el progreso y una supervivencia humana sostenible", parafraseando la introducción de los documentos de la Cumbre de la Tierra (ONU 1992).

A finales del siglo XVIII, el economista y demógrafo inglés Thomas Robert Malthus publicó un ensayo sobre el Principio de Población que tiene profundas raíces ambientales. Dicho ensayo se resume en que "Alimentos y población se encuentran en una relación inversa por una diferente progresión de crecimiento. La población crece en progresión geométrica, mientras los alimentos lo hacen en progresión aritmética" (TARINGA p.e). Dicho en otras palabras: si la población crece más rápidamente que los recursos, la población empobrece de manera progresiva y se agotan los recursos naturales, con las consecuencias negativas para el medio ambiente.

La preocupación humana por su entorno a menudo se ha traducido en normas ambientales cuya evolución ha seguido diversas etapas (hasta cuatro según algunos actores). La primera, comprende los preceptos orientados en función de los usos de un recurso (suelos, aguas, bosques u otros). La segunda, más evolucionada, encuadra la legislación en función de cada categoría o especie de recurso natural, pero coordinándolo con los distintos usos (agricultura, riego, aprovechamiento forestal, etc.). La tercera orienta la normativa hacia el conjunto de los recursos naturales. Finalmente, la cuarta etapa toma en consideración el entorno como un conjunto global y atiende a los ecosistemas. Esta última comprende las normas ambientales en sentido estricto (FAO 1999, citado por Vallejo 2014).

Estas etapas del perfeccionamiento legislativo, aunque sucesivas, no se excluyen unas a otras. El Derecho Ambiental se desarrolló como lógica respuesta a la necesidad de explotar los recursos naturales en un marco de racionalidad, aprovechamiento sostenible y protección del ambiente. Su evolución ha sido rápida y progresiva, incorporándose gradualmente en todas las ramas jurídicas y adquiriendo, a su vez, autonomía propia como disciplina vinculada con casi todas las demás ciencias, no solo las del Derecho sino que con las ciencias naturales, sociales, económicas, etc. De allí que una de las características del Derecho Ambiental sea su sustrato metajurídico, porque antecede y trasciende a las relaciones jurídicas. 


\section{B. Situación ambiental en el tercer milenio}

En un estudio del Programa de las Naciones Unidas para el Medio Ambiente (PNUMA), se concluye que "A nivel global hay dos tendencias fundamentales que caracterizan el comienzo del tercer milenio. Primero, el ecosistema mundial se ve amenazado por graves desequilibrios en la productividad y en la distribución de bienes y servicios. Segundo, el mundo se está transformando a un ritmo cada vez más acelerado, pero en ese proceso la gestión ambiental, que tiene su fundamento en la normativa jurídica, está retrasada con respecto al desarrollo económico y social" (PNUMA 1999). El mismo informe establece claramente que en caso de que continúen las tendencias actuales del aumento de la población, el crecimiento económico y las pautas de consumo, las presiones en el medio ambiente natural serán cada vez mayores. Algunas estadísticas...

- El ingreso per cápita mundial medio actual es superior a los 5.000 dólares EE.UU. por año, pero más de 1.300 millones de personas todavía viven con menos de 1 dólar por día.

- Si bien en el decenio 1988-1997 los gastos militares en todo el mundo disminuyeron en un promedio del $4,5 \%$ anual, los graves conflictos armados han ejercido una mayor presión en los ecosistemas.

- El sector privado puede influir enormemente en el resultado de las cuestiones ambientales. En 1996, la inversión privada fue de aproximadamente 250.000 miIlones de dólares, mientras que la asistencia para el desarrollo de ultramar fue inferior a 50.000 millones de dólares.

- Los esfuerzos necesarios para satisfacer las necesidades de recursos naturales de los 3.000 millones de personas que se sumarán a la poblacion mundial en los próximos 50 años serán inmensos.

A fin de poder asignar recursos suficientes para atender a las necesidades de los países en desarrollo será necesario establecer como objetivo de largo plazo que los países industrializados reduzcan a una décima parte su consumo de recursos (Fuente: PNUMA 1999).

En los documentos de la Cumbre de la Tierra (ONU 1992) se advirtió que probablemente, el ritmo y la escala del crecimiento demográfico y económico mundial, eran causas subyacentes de los grandes problemas ambientales que afectaban el planeta a finales del siglo XX. Los siete mil millones de pobladores de la tierra - se dijo- están explotando colectivamente los recursos del globo "a tasas e intensidades crecientes que sobrepasan la capacidad de sus sistemas para absorber residuos y neutralizar los efectos adversos sobre el ambiente. De hecho, el agotamiento o la degradación de varios recursos clave están ya limitando el desarrollo convencional 
en algunas regiones del mundo".

Al mismo tiempo se señaló que el planeta esta siendo severamente alterado por las actividades humanas causando severos cambios como el incremento de la temperatura global y de los niveles del mar y la acidificación de los océanos, todos ellos asociados al aumento en las emisiones de gases de efecto invernadero. Otros cambios provocados por las actividades humanas incluyen la extensa deforestación y desmonte para dedicar la tierra a la agricultura y urbanización, causando extinción de especies conforme se destruyen hábitats naturales.

\section{Algunas estadísticas...}

- $\quad$ El ingreso per cápita mundial medio actual es superior a los 5.000 dólares EE.UU. por año, pero más de 1.300 millones de personas todavía viven con menos de 1 dólar por día.

- $\quad$ Si bien en el decenio 1988-1997 los gastos militares en todo el mundo disminu yeron en un promedio del $4,5 \%$ anual, los graves conflictos armados han ejercido una mayor presión en los ecosistemas.

- $\quad$ El sector privado puede influir enormemente en el resultado de las cuestiones ambientales. En 1996, la inversión privada fue de aproximadamente 250.000 millones de dólares, mientras que la asistencia para el desarrollo de ultramar fue inferior a 50.000 millones de dólares.

- Los esfuerzos necesarios para satisfacer las necesidades de recursos naturales de los 3.000 millones de personas que se sumarán a la población mundial en los próximos 50 años serán inmensos.

- $\quad$ A fin de poder asignar recursos suficientes para atender a las necesidades de los países en desarrollo será necesario establecer como objetivo de largo plazo que los países industrializados reduzcan a una décima parte su consumo de recursos. (Fuente: PNUMA 1999).

\section{Problemática ambiental mundial}

En la Cumbre de la tierra se logró identificar los grandes problemas ambientales que a finales del milenio afectaban a nivel global: el cambio climático, pérdida de la diversidad biológica, deforestación y ruptura de la capa de ozono, a los que se sumaban otros problemas de impacto regional (un continente, subcontinente, etc.) o para determinadas especies (maderas tropicales, especies en vías de extinción) o elementos ambientales específicos (residuos, sustancias tóxicas o peligrosas, entre otras).

En la Declaración de Río fueron definidos los derechos y las obligaciones de los Estados 
respecto de principios básicos sobre el medio ambiente y el desarrollo, incluyendo ideas como que: la falta de certeza científica no debe demorar la adopción de medidas de protección del medio ambiente (principio de Precaución); los Estados tienen el "derecho soberano de aprovechar sus propios recursos" pero no a causar daños al medio ambiente de otros Estados (evaluación de impactos transfronterizos); la eliminación de la pobreza y la reducción de las disparidades en los niveles de vida en todo el mundo son indispensables para el desarrollo sostenible, y la plena participación de la mujer es imprescindible para lograr el desarrollo sostenible. $^{2}$

Un resultado concreto de esta Cumbre, desde la perspectiva jurídica, es que se abrieron a la firma dos instrumentos con fuerza jurídica obligatoria: la Convención Marco sobre el Cambio Climático y el Convenio sobre la Diversidad Biológica. Al mismo tiempo se iniciaron negociaciones con miras a una Convención de Lucha contra la Desertificación y un poco más tarde a la Convención Marco de las Naciones Unidas para la Protección de la Capa de Ozono.

\section{CAPÍTULO II CONTEXTO AMBIENTAL EN HONDURAS}

\section{A. Situación ambiental del País}

Los recursos naturales hondureños representan un potencial que genera datos interesantes para el desarrollo del país. Entre otros beneficios, el suelo, eminentemente forestal, alberga una rica biodiversidad, combinado con la riqueza del subsuelo por la variedad de minerales. Las aguas son fuente de importantes recursos marino costeros y un todavía no cuantificado potencial en hidrocarburos. Todo lo anterior es sinónimo de riqueza y bienestar si se aprovecha en el marco de un desarrollo sostenible.

De acuerdo a un estudio elaborado por el Ministerio de Recursos Bosques en 1962, las tierras de vocación forestal natural de Honduras cubrían el $87 \%$ del territorio nacional (COHDEFOR 1996). Actualmente, solo un $59 \%$ del suelo hondureño está cubierto de bosques $(6,598,289$ hectáreas). De éstas, 57\% están cubiertas de bosques latifoliados, 38\% de coníferas y el resto corresponde a bosque mixto, manglares y bosque seco (ICF 2013). Este recurso forestal se puede aprovechar para obtener productos directos como madera, resina, aceites y semillas, para proveer bienes y servicios ambientales y para conservación y protección de la biodiversi-

\footnotetext{
${ }^{2}$ La Cumbre de la Tierra, celebrada en Río de Janeiro, Brasil, entre el 3 y el 14 de junio de 1992, reunió a 172 gobiernos, incluidos 108 Jefes de Estado y de Gobierno. Se aprobaron tres grandes acuerdos que habrían de regir la labor futura: el Programa 21, un plan de acción mundial para promover el desarrollo sostenible; la Declaración de Río sobre el Medio Ambiente y el Desarrollo, un conjunto de principios en los que se definían los derechos civiles y obligaciones de los Estados, y una Declaración de principios relativos a los bosques, serie de directrices para la ordenación más sostenible de los bosques en el mundo
} 
dad. Muestras de todos los ecosistemas forestales y otros afines se conservan mediante las 94 áreas protegidas que han sido declaradas legalmente por el Congreso Nacional.

Respecto a la biodiversidad, en el "Estudio sobre Diversidad Biológica de la República de Honduras" (Cirilo Nélson, citado en Geo Honduras 2005) se manifiesta que la riqueza biológica del país conocida hasta la fecha representa el $2.5 \%$ de la flora mundial, la cual es de aproximadamente 300,000 especies de plantas vasculares. En cuanto a la diversidad de fauna en Honduras, hasta la fecha se han reportado 537 especies de invertebrados marinos. Asimismo se han reportado 2,500 especies de insectos, sin embargo varios autores estiman que podría existir un mayor número, ya que estos estudios han sido dirigidos principalmente a insectos de importancia para los cultivos agrícolas y forestales (SERNA 2005). Esta biodiversidad genera beneficios a la sociedad, tanto económicos, como sociales y ambientales, entre estos la provisión de provee alimentos, agua en calidad y cantidad para diferentes usos, medicinas, riqueza escénica, entre otros bienes y servicios.

Honduras también posee gran riqueza de ecosistemas marino costeros, contando con 804 kilómetros de playa de costa en el Caribe y el Pacífico. En la primera está el Arrecife del Caribe Mesoamericano, considerado el segundo más importante a nivel mundial y en la segunda el Corredor Biológico del Pacífico, conformado por 10 áreas protegidas que están registradas como el Sitio Ramsar número $1000 .{ }^{3}$ Los humedales, propios de estos sistemas, son lugares de almacenamiento de material genético vegetal, sosteniendo actividades económicas como la camaricultura y la pesca y son un refugio para varias especies en peligro de extinción como la tortuga golfina, el manatí, el tiburón ballena, cocodrilo, curil y casco de burro (SERNA op cit). Por otra parte, en el mapa con ubicación de minerales en Honduras se indica que existen 141 unidades de minerales metálicos que cubren desde los depósitos de oro, plata, antimonio, mercurio y hierro, hasta los polimetálicos.

Con el auge de la actividad minera en los últimos años se ha activado la explotación a gran escala de oro y plata en minas en los departamentos de Choluteca, Copán, Francisco Morazán y Valle, sumándose a la tradicional mina polimetálica "El Mochito". Además, existe una gran cantidad de explotaciones mineras en forma artesanal. Por otra parte, los minerales no metálicos suman en total 30 depósitos que corresponden a carbón, barita, mármol, cal, yeso, bentonita, ópalo, sílice y obsidiana. De estos, las canteras de mármol y cal son las más explotadas (SOPTRAVI 1996).

${ }^{3}$ RAMSAR: Convención Relativa a los Humedales de Importancia Internacional Especialmente como Hábitat de Aves Acuáticas. 
No obstante la riqueza proveniente de los recursos naturales y elementos afines, la situación ambiental general del país ha sido objeto de preocupación desde hace varias décadas. Donde quizás se manifiesta mejor esta preocupación es en la cita que se hace en un informe de la FAO: "Situado en la ruta de tormentas tropicales y huracanes, Honduras, según datos del PNUD es uno de los 20 países más vulnerables del mundo en cuanto a inundaciones y el más vulnerable a los huracanes. A lo largo de su historia, las graves consecuencias de las amenazas hidrometeorológicas han causado en Honduras enormes pérdidas humanas, sociales, económicas y ambientales" (FAO p.e.).

Esta preocupación hizo que a principios de los años noventa, mediante acuerdo presidencial fuera creada la Comisión Nacional de Medio Ambiente (CONAMA), que evolucionó luego a Secretaría del Ambiente en 1993, a la que se agregó más tarde el despacho de Recursos Naturales en 1996 y el de Energía en 2013. Hoy, la Secretaría de Energía, Recursos Naturales y Ambiente es la autoridad responsable la gestión ambiental en el país y de enfrentar los múltiples problemas que se suceden es su ámbito de acción.

De acuerdo a la ley, esta Secretaría de Estado tiene las competencias fundamentales de: "formular, coordinar, ejecutar y evaluar las políticas relacionadas con la protección y aprovechamiento de los recursos hídricos, las fuentes nuevas y renovables de energía, todo lo relativo a la generación y transmisión de energía hidroeléctrica y geotérmica así como a la actividad minera y a la exploración y explotación de hidrocarburos". Además, todo lo que atañe a: "la coordinación y evaluación de las políticas relacionadas con el ambiente, los ecosistemas, el sistema nacional de áreas naturales protegidas y la protección de la flora y la fauna, así como los servicios de investigación y control de la contaminación en todas sus formas". (Artículo 29 de la Ley General de la Administración Pública, reformada por el Decreto 218-96 del 7 de diciembre de 1996).

Otra serie de instituciones asumen también sus propias responsabilidades en la gestión ambiental en su respectiva jurisdicción, entre las cuales las que administran los recursos naturales, en especial la Secretaría de Agricultura y Ganadería (SAG) y el Instituto Nacional de Conservación Forestal, Áreas Protegidas y Vida Silvestre (ICF), pero dando preponderancia también a la Secretaría de Salud y las municipalidades, que asumen responsabilidades legales en materia de ambiente. Sin embargo, si se revisa las competencias de las diferentes instituciones públicas, fácilmente se encontrará que de una u otra forma tienen funciones relacionadas con el ambiente. Tampoco está ajena la gestión ambiental el resto de la sociedad (organizaciones no gubernamentales, empresa privada y otros sectores).

\section{B. Principales problemas ambientales}


Pese a que Honduras posee recursos naturales y elementos ambientales que en otros países serían sinónimo de riqueza y bienestar, la problemática ambiental es aguda en cada uno de los sectores vistos como potencial de desarrollo en la sección anterior. En un estudio para el Banco Mundial, hecho en el contexto del uso potencial del territorio, se señala que los problemas ambientales clave en Honduras son: degradación de los recursos forestales y la biodiversidad; uso y degradación de los suelos; contaminación y manejo del agua; contaminación del aire; generación de basuras en las municipalidades; vulnerabilidad a desastres y fenómenos naturales (Falck 2007). En cada uno de ellos hay un sinnúmero de causas directas y subyacentes que contribuyen a la vulnerabilidad ambiental del país y a la explotación inequitativa de los recursos naturales que significa más pobreza y espacios para que segmentos de la población agredan por necesidad al ambiente.

Siguiendo los sectores señalados con potencial en la sección anterior se determina que en el Sector Forestal la falta de gobernanza ha conducido a altas tasas de deforestación y degradación de los bosques y la posible pérdida de especies de flora y fauna cuyos beneficios para la sociedad nunca serán conocidos porque no hubo oportunidad de estudiarlas. Un estudio reciente señala como principales causas de deforestación y degradación: las políticas públicas, marco legal deficiente, institucionalidad débil, técnicas mal utilizadas, inequidad social y una cultura forestal sin raíces (GIZ 2011).

Las causas directas más conocidas son: tala y comercio ilegal de productos forestales, incendios forestales, extracción de leña para energía.

Concretamente sobre la pérdida de biodiversidad se imputa como causas principales o directas a la tala y comercio ilegal de madera, la sobreexplotación comercial de la flora y fauna silvestre, el uso desmedido y descontrolado de la leña como fuente energética, la contaminación ambiental en los componentes agua, aire y suelo, los movimientos migratorios internos, la urbanización y el rápido crecimiento de las ciudades grandes y medianas.

Las aguas y los recursos marino-costeros son objeto de conflictos de uso y acceso. La situación se agrava por la falta de políticas integrales y leyes adecuadas y aplicables. En SERNA Op cit se afirma que la presión sobre las cuencas hidrográficas la ejercen las prácticas inadecuadas de producción y ampliación de la frontera agrícola (agricultura y ganadería), inseguridad en la tenencia de la tierra, presión sobre la administración del agua y el proceso inadecuado de explotación forestal, mientras que en los recursos marino costeros causan problemas la sobrexplotación, el acceso limitado a los bancos de pesca, entre otros.

Los problemas relacionados con la minería se describen en el "Diagnóstico de la situación minera en Honduras 2007-2012" donde se señala como causas de la conflictividad en ese sector "enfrentamiento de las empresas mineras con las comunidades, bajos niveles de con- 
tribución a impuestos nacionales y municipales, problemas ambientales, violaciones a los derechos humanos, un marco legal débil y favorable a las compañías, mineras y una institucionalidad estatal débil para regular las actividades extractivas" (ICEFI 2014).

La suma de lo anterior hace que a nivel nacional queden reflejados los grandes problemas ambientales globales: pérdida de biodiversidad, cambio climático y desertificación y los especiales que significa la exposición de especies de flora y fauna al peligro de extinción.

\section{Respuestas del Derecho a la Problemática Ambiental en Honduras}

A los esfuerzos institucionales por afrontar la problemática ambiental se debe sumar la contribución del Derecho en general y particularmente de la legislación nacional e internacional.

\section{1.- Contexto legal ambiental internacional}

En el Compendio de Compromisos Internacionales en Materia de Ambiente (SERNA 2004) la Secretaría de Recursos Naturales y Ambiente incluye más de 50 convenios o tratados internacionales vinculados al ambiente, que han cumplido con todo el procedimiento para convertirse en ley nacional vigente, de conformidad con el Artículo 16 de la Constitución de la República, o sea, han sido aprobados por el Congreso Nacional, ratificados por el Poder Ejecutivo y publicados en el Diario Oficial "La Gaceta". Quedan fuera del listado anterior los convenios, declaraciones, principios u otras acciones derivadas de acuerdos políticos que no han sido sometidas a la aprobación del Congreso Nacional, que son conocidas como Derecho Blando o "soft law", como la Agenda 21, las declaraciones de Río de Janeiro, principios forestales de reuniones presidenciales, Ronda de Montevideo y otras. Estas, a pesar de que constituyen una base de entendimiento internacional, carecen de la coercitividad que es inherente a las normas jurídicas.

Según USAID/MIRA 2008, los primeros tratados aprobados fueron: Convención Internacional para la Seguridad de la Vida Humana en el Mar (Decreto 18, La Gaceta del 19 de agosto de 1968); Prohibición del Desarrollo, Producción y Almacenamiento de Armas Bacteriológicas, Biológicas y Tóxicas sobre su Destrucción (Decreto 581, La Gaceta del 19 de diciembre de 1978); Comercio Internacional de Especies Amenazadas de Flora y Fauna Silvestre, CITES (Decreto 771, La Gaceta del 24 de septiembre de 1979) y el Convenio sobre Vertimiento de Desechos en el Mar (Decreto 844, La Gaceta del 6 de febrero de 1980).

En la década de los noventa, posiblemente como una consecuencia de los compromisos asumidos por el país en la Cumbre de la Tierra en 1992, fueron aprobados la mayoría de 
los tratados que actualmente se aplican en materia de ambiente, entre ellos los que tratan los problemas ambientales globales: Convenio de Viena para la Protección de la Capa de Ozono (Decreto 73-93, La Gaceta del 21 de agosto de 1993), Convención marco de las Naciones Unidas sobre Cambio Climático (Decreto 26-95, La Gaceta del 29 de julio de 1995), Convenio sobre Diversidad Biológica (Decreto 30-95, La Gaceta del 10 de junio de 1995) y Convenio de Lucha contra la Desertificación en los Países Afectados por la Sequía Grave o Desertificación (Decreto 35-97, La Gaceta del 24 de junio de 1997). Por su relevancia y actualidad también es relevante mencionar el Convenio 169 sobre Pueblos Indígenas y Tribales en Países Independientes (Decreto 26-94, La Gaceta del 30 de julio de 1994) y el Convenio de Estocolmo sobre Contaminantes Orgánicos Persistentes (Decreto 24-2004, La Gaceta del 23 de abril de 2005).

Por último, en el contexto legal internacional es importante referir que los tratados de libre comercio de última generación, como el TLC entre Centroamérica-Estados Unidos de América y República Dominicana, CAFTA-DR (Decreto 10-2005, del 3 de marzo de 2005) y el más reciente Acuerdo de Asociación Centroamérica-Unión Europea (Decreto 210-2013), ${ }^{4}$ incluyen un capítulo ambiental, que, por primera vez, es jurídicamente vinculante. En esencia este capítulo se contrae a que cada Estado parte se compromete a cumplir con toda la legislación ambiental del país. ${ }^{5}$

\section{2.- Disposiciones ambientales en la Constitución de la República}

La Constitución de la República de Honduras contiene ideas fundamentales de carácter general, de las cuales emanan leyes ordinarias sobre los diferentes tópicos entre ellos los que aplican a la materia de ambiente. Un estudio no muy exhaustivo permite identificar casi treinta artículos constitucionales que se aplican, directa o indirectamente, a la materia ambiental o los recursos naturales. "De la revisión realizada a la Constitución de la República se logró establecer relaciones ambientales en los artículos siguientes: 103 a 107; 128, 145, 187, 246, 274; 301, y 339 a 354, aunque otros pueden incluirse por alguna relación indirecta" (Vallejo 2014). En estos artículos la Constitución de la República hace alusión directa a los temas de propiedad en general, salud, institucionalidad ambiental y sectorial sobre recursos naturales, aprovechamiento de los recursos naturales y derechos de los pueblos indígenas y

\footnotetext{
4 No publicado en La Gaceta sino que con autorización del Congreso Nacional se publicó en el portal electrónico: www. prohonduras.hn. Abog. Jorge Pinel Turcios. Aspectos Legales de Política Comercial SIC. Comunicación Personal.

${ }^{5}$ Para un mejor conocimiento de este tema se sugiere revisar el Compendio aplicado: Legislación con enfoque en Comercio y Ambiente, publicado en 2008 por el Proyecto USAID/MIRA
} 
afrohondureños a estos recursos.

El único artículo constitucional que hace alusión expresa al ambiente es el 145 que en su redacción original afirma que "es un deber del Estado la conservación del medio ambiente adecuado para proteger la salud de las personas", en un claro reconocimiento al derecho humano básico a un ambiente sano que tienen todos los ciudadanos y residentes bajo cualquier condición en el país. En 2013, este artículo fue reformado, adicionando al texto original la declaración de que el acceso al agua y saneamiento es un derecho humano y su aprovechamiento y uso debe ser equitativo, dando preferencia a su uso para consumo humano y garantizando al mismo tiempo, la preservación de las fuentes de agua de forma que estas se mantengan libres de contaminación y de actividades que pongan en riesgo la vida y la salud de las personas (Decreto 232-2012, publicado en La Gaceta del 24 de enero de 2013).

\section{3.- Disposiciones ambientales en la legislación nacional secundaria}

Sería muy laborioso tratar de mencionar todas las disposiciones ambientales contenidas en la legislación nacional secundaria. Vallejo 2014 menciona que al menos hay 100 leyes a este nivel que aplican a temas de ambiente bajo dos categorías: leyes ambientales propiamente dichas (Ley General del Ambiente y los reglamentos que se derivan directamente de aquella); y leyes que regulan recursos naturales (suelos, agua, bosques) u otros elementos ambientales (turismo, patrimonio nacional, contaminación, residuos, etc.). Lo anterior sin contar las normas que sin ser ambientales contienen disposiciones aplicables a esta temática (Códigos: Civil, Penal, Mercantil, Salud, Ley de Municipalidades, leyes administrativas, entre otros).

\section{a.- Leyes ambientales propiamente dichas}

En la categoría de leyes ambientales propiamente dichas se ubica como única la Ley General del Ambiente (Decreto 104-93 del 27 de mayo de 1993), pero la misma ha sufrido una serie de reformas que se debe tomar en cuenta porque en ellas se modifican diferentes partes (estructura orgánica, procedimientos, tasas a cobrar por licencias ambientales, simplificación de algunos trámites, etc.). También tiene un solo reglamento general (Acuerdo 109-93, del 20 de diciembre de 1993), con la advertencia de que se debe utilizar con sumo cuidado, porque no están incorporadas las reformas de la ley en su base reglamentaria. Por lo demás, hay otros reglamentos que se derivan directamente de la Ley General del Ambiente o en combinación con autoridades sectoriales. Cinco de estos reglamentos se mencionan a continuación: 
1) Reglamento para el manejo integral de residuos sólidos (Acuerdo 1567-2010, La Gaceta del 22 de febrero de 2011).

2) Reglamento de Auditorías Ambientales (Acuerdo 887-2009, La Gaceta del 15 de enero de 2010).

3) Reglamento de Prestadores de Servicios Ambientales (Decreto PCM 8262009, del 15 de enero de 2010).

4) Reglamento del Sistema de Evaluación de Impactos Ambientales, SINEIA (Acuerdo 189-2009, La Gaceta del 31 de diciembre de 2009).

5) Reglamento General de Salud Ambiental (Acuerdo 094-97,11junio 2007).

\section{b.- Leyes que regulan recursos naturales y otros elementos ambientales}

En esta tipología se ubica una gran cantidad de normas legales, de tal forma que su sola mención es casi imposible en un artículo de revista, lo más que se puede aspirar es hacer una clasificación que permita mencionar las principales. Por ejemplo, en la estructura de la Ley General del Ambiente se distribuyen los temas en recursos naturales y elementos ambientales distintos a los recursos naturales. En la primera temática se ubica las aguas continentales y marítimas, la protección de la naturaleza (bosques, áreas protegidas y vida silvestre), los suelos (de uso agrícola, pecuario y forestal y de uso urbano e industrial), los recursos marinos y costeros y los minerales e hidrocarburos; en la segunda están: atmósfera, residuos sólidos y orgánicos, productos agroquímicos, tóxicos y peligrosos, patrimonio histórico, cultural y recursos turísticos, ambiente y salud humana.

Para entender la complejidad del entorno jurídico ambiental en esta categoría (recursos naturales y elementos ambientales distintos a los recursos naturales) hay que pensar que en cada uno de los temas señalados en las subcategorías existe una serie de leyes, reglamentos y normas técnicos que es necesario conocer cuando se pretenda aplicar la ley al caso concreto.

Solo a guisa de ejemplo se menciona a continuación las leyes aplicables a los principales recursos naturales, que de alguna manera han sido mencionados en forma reiterada en este artículo: suelos (de uso agrícola, pecuario y forestal y de uso urbano e industrial y el subsuelo), aguas (continentales y marítimas) y bosques (áreas protegidas y vida silvestre), entendiendo que cada uno de ellos, además de uno o más tratados internacionales, tiene un número indeterminado de reglamentos y normas legales o técnicas. 
1) Suelos (de uso agrícola, pecuario y forestal y de uso urbano e industrial y el subsuelo)

\begin{tabular}{|c|c|}
\hline Nombre de la Norma Legal & $\begin{array}{l}\text { Tipo de Resolución } \\
\text { (Fecha de publicación en La Gaceta) }\end{array}$ \\
\hline Ley de Ordenamiento Territorial & Decreto 180-2003 (30 de Diciembre de 2003) \\
\hline Ley de Propiedad & Decreto 82-2004 (20 de Junio de 2004) \\
\hline Ley para la Modernización y Desarrollo del Sector Agrícola & Decreto 31-92 (6 de Abril de 1992) \\
\hline Ley de Expropiación Forzosa & Decreto 113 (9 de Mayo de 1914) \\
\hline $\begin{array}{l}\text { Ley Especial de Inversiones Agrícolas y Generación de Empleo } \\
\text { Rural }\end{array}$ & Decreto 222-98 (20 de Enero de 1999) \\
\hline Ley Forestal de las Áreas Protegidas y la Vida Silvestre & Decreto 98-.07 (26 de Febrero de 2008) \\
\hline Ley General de Minería & Decreto 238-2012 (2 de abril de 2013) \\
\hline Ley de Protección a la Actividad Caficultora & Decreto 199-95 (1 de Marzo de 1995) \\
\hline Ley de Reforma Agraria & Decreto 170 (8 de Enero de 1975) \\
\hline Ley General del Ambiente & Decreto 104-93 (30 de Junio de 1993) \\
\hline $\begin{array}{l}\text { Ley para adquisición de bienes que regula el Artículo } 107 \text { de la } \\
\text { Constitución de la República }\end{array}$ & Decreto 90-90 (27 de Agosto de 1990) \\
\hline
\end{tabular}

2) Aguas (continentales y marítimas)

\begin{tabular}{|l|l|}
\hline \multicolumn{1}{|c|}{ Nombre de la Norma Legal } & \multicolumn{1}{c|}{$\begin{array}{c}\text { Tipo de Resolución } \\
\text { (Fecha de publicación en La Gaceta) }\end{array}$} \\
\hline Ley General de Aguas & Decreto 181-2009 (14 de diciembre 2009) \\
\hline Ley Marco de Agua Potable y Saneamiento & Decreto 118-2003 (8 de Octubre 2003) \\
\hline Ley de Pesca & Decreto 154 (17 de Junio de 1959) \\
\hline Ley sobre el Aprovechamiento de los Recursos Naturales del Mar & Decreto 921 (13 de Junio de 1980) \\
\hline Ley Forestal, Áreas Protegidas y Vida Silvestre & Decreto 98-.07 ( 26 de Febrero de 2008) \\
\hline Ley General del Ambiente & Decreto 104-93 (30 de Junio de 1993) \\
\hline Código de Salud & Decreto 65-91 (6 de Agosto de 1991) \\
\hline Ley de Marina Mercante & Decreto 167-94 (2 de Enero de 1995) \\
\hline Ley de Municipalidades & Decreto 134-90 (29 de Octubre 1990) \\
\hline Ley Marco del Subsector Eléctrico & Decreto 158-94 ( 26 de Noviembre 1994) \\
\hline $\begin{array}{l}\text { Ley para adquisición de bienes urbanos que delimita el Artículo } \\
\text { 107 de la Constitución de la República }\end{array}$ & Decreto 090-90 (27 de Agosto de 1990) \\
\hline
\end{tabular}


3) Bosques (áreas protegidas y vida silvestre)

\section{Nombre de la Norma Legal}

Ley Forestal de las Áreas Protegidas y la Vida Silvestre

"Ley de Bosques Nublados"

Ley de Municipalidades

Ley de Propiedad

Ley General del Ambiente

Ley General de Minería

Otras Leyes que crean Áreas Protegidas

\section{Tipo de Resolución}

(Fecha de publicación en La Gaceta)

Decreto 98-.07 (26 de Febrero de 2008)

Decreto 87-87 (5 de Agosto de 1987)

Decreto 134-90 (29 de Octubre 1990)

Decreto 82-2004 (29 de Junio de 2004)

Decreto 104-93 (30 de Junio de 1993)

Decreto 238-2012 (2 de abril de 2013)

Varios

\section{CAPÍTULO III AMENAZAS Y OPORTUNIDADES}

\section{A.- Obstáculos para aplicar la Legislación Ambiental y opciones para mejorar}

La cantidad y dispersión de la normativa aplicable al ambiente y los recursos naturales permite visualizar varios obstáculos entre los cuales se puede mencionar: 1) desconocimiento de de los principios básicos del Derecho Ambiental y de la legislación vigente para casos ambientales o de recursos naturales; 2) falta de tratamiento de la problemática ambiental en la academia; 3) el sistema de aplicación de la normativa ambiental es deficiente en sus diferentes esferas o niveles; 4) prevalece la percepción de que las malas conductas o prácticas ambientales se pueden resolver por medio del sistema sancionatorio, relegando la opción de propiciar cambios mediante estímulos para evitar que el ciudadano incumpla la ley.

1.- La falta de conocimiento sobre cuáles leyes existen de acuerdo al caso concreto puede conducir a elegir una que sea inadecuada, no sólo desde la perspectiva jurídica tradicional, sino que de acuerdo a los principios que buscan conservar el ambiente, para evitar esto se requiere de conocimientos técnicos básicos para su aplicación de forma efectiva, en especial en el ámbito administrativo. Este conocimiento debe incluir los principios y características del Derecho Ambiental que puede resultar diferente a las demás disciplinas del derecho, en especial el Principio de Precaución establecido en la Declaración de Río (Cumbre de la Tierra): “Con el fin de proteger el medio ambiente, los Estados deberán aplicar ampliamente el criterio de precaución conforme a sus capacidades. Cuando haya peligro de daño grave o irreversible, la falta de certeza científica absoluta no deberá utilizarse como razón para postergar la adopción de medidas eficaces en función de los costos para impedir la degradación del 
medio ambiente". O sea, que aunque no haya evidencias prácticas sobre daños potenciales al ambiente se debe establecer todas las normas que se consideren necesarias para prevenir la ocurrencia de resultados perjudiciales.

2.- Entre las instancias responsables de colaborar en la conservación ambiental la academia deviene obligada a establecer políticas para el tratamiento de la problemática ambiental en general y en el respectivo espacio del sistema educativo donde le toque actuar. La UNAH, como parte de su misión asume el compromiso de "contribuir a través de la formación de profesionales, la investigación y la vinculación universidad-sociedad al desarrollo humano sostenible del país" (UNAH P.e.), ello sin duda implica la decisión de propiciar la formación ambiental de los docentes no solo en la UNAH, sino que en todas las universidades, y de potenciar la educación ambiental en las diferentes facultades o centros de estudio. En consecuencia, las universidades deben adoptar una política de inserción del componente ambiental ajustada a las carreras que imparten (en la facultades de Derecho por ejemplo, se deberá propiciar que sus estudiantes tengan la adecuada formación ambiental que les permita adaptarse mejor a la sociedad de hoy y expandir el abanico de sus oportunidades laborales. Lo anterior puede ser mediante cátedras especializadas, diplomados, posgrados u otras modalidades).

3.- El sistema de aplicación de la normativa ambiental es deficiente en sus diferentes esferas o niveles y en general existe una tendencia a pensar que la problemática ambiental se va a resolver imponiendo sanciones a los infractores, sin meditar en que muchas veces las causas subyacen en la pobreza o el desconocimiento. Hay debilidad en la jurisdicción administrativa, que carece de personal y recursos en general para dar seguimiento a sus propios permisos o licencias y en el sistema judicial las causas ambientales se relegan ante el volumen de los delitos comunes. La tendencia a dar preferencia al sistema sancionatorio tiene además otros problemas, como que el conocimiento de las infracciones ambientales (delitos o faltas) requiere de medios de prueba cuyo costo y dificultad científica no están al alcance de las instituciones públicas y de que, particularmente en el ámbito judicial, se carece de especialidad para el conocimiento de las mismas. En la misma medida el sistema sancionatorio se vuelve ineficiente.

4.- La percepción de que las malas conductas o prácticas ambientales se pueden resolver por medio del sistema sancionatorio relegan la opción de propiciar cambios mediante estímulos para evitar que el ciudadano incumpla la ley. Es común que el profesional del Derecho y en general, los funcionarios públicos y el ciudadano común, conozcan las figuras delictivas tipificadas en las diferentes leyes, aduciendo muchas veces su liviandad y falta de aplicación, pero en cambio, los diferentes incentivos legales, pese a que están contenidos en muchas leyes y contribuirían a la mejor aplicación de la legislación y la conservación ambi- 
ental, son desconocidos y poco atractivos para ser aplicados. Tal apreciación es equivocada porque con las sanciones difícilmente se logra resarcir el daño ambiental causado, y por lo general, el inculpado se vuelve hostil ante la causa ambiental. Por otra parte, la utilización de incentivos que le permitan acceder a beneficios sociales por su contribución voluntaria a la gestión ambiental, o económicos por el acceso a mecanismos de compensación por las buenas prácticas ambientales, se logra tener aliados para la conservación ambiental.

\section{B. Oportunidades para el profesional del Derecho}

En Honduras históricamente la formación del profesional universitario del Derecho se ha orientado a las disciplinas que más demandaba la sociedad y donde había mejor expectativas laborales (administrativo, civil, laboral penal y procesal). En muchos países, la tendencia actual en la academia es abordar con seriedad el tema de ambiente o sus conceptos afines (desarrollo sostenible, ordenamiento territorial, etc.). Conviene por lo tanto, analizar la conveniencia de formar profesionales con orientación en Derecho Ambiental en las facultades de Derecho del país. Con lo anterior se estará ofreciendo mejores oportunidades de trabajo al profesional y mejor calidad al servicio del ambiente y los ecosistemas.

En la Administración Pública es necesaria la participación de profesionales que realicen la parte legal del análisis de los instrumentos ambientales presentados por los proyectistas de obras, actividades o proyectos que requieren de licencias o controles ambientales. Además, como asesores legales en las diferentes instituciones que realizan funciones de gestión ambiental o de los recursos naturales. En la empresa privada, organizaciones civiles sin fines de lucro y entidades representativas de los pueblos autóctonos, además de las funciones propias de representación, los profesionales del Derecho pueden ser un apoyo para los prestadores de servicios ambientales que deben incorporar la normativa ambiental en los mismos instrumentos que se someten para la aprobación de la autoridad ambiental. En ambos casos, con la debida formación estos profesionales pueden ser parte de centros de conciliación o tribunales de arbitraje en materia ambiental.

La sola opción de un programa dirigido a una formación de los cuadros actuales en los diferentes sectores representa un reto para la academia y una oportunidad de desarrollo profesional de los colegas empleados o para quienes prestan sus servicios en forma independiente, con la ventaja de que se abren nuevas oportunidades para las nuevas generaciones, igual que programas orientados a las nuevas generaciones de profesionales del Derecho, que con mejor información pueden encontrar nuevas avenidas de trabajo que les signifiquen una oportunidad de desarrollo personal. Las competencias y calificaciones en el campo profesional son un indicador de crecimiento individual pero también de mejoras salariales. 


\section{CONCLUSIONES}

A. ¿Qué percepción hay sobre el Derecho Ambiental en Honduras?

1.- Las preocupaciones, que a nivel mundial han causado las tendencias del crecimiento económico, aumento de la población y las pautas de consumo, llegan también a Honduras, al menos por las dos últimas tendencias y como consecuencia de la creciente pobreza, inequidad social e ineficientes sistemas de administración de los recursos naturales. Las actividades humanas con fines productivos provocan elevadas altas tasas de deforestación y contaminación en muchos lugares el país, lo mismo que el cambio de uso del suelo para dedicar la tierra a la agricultura, agroindustria y la urbanización, causando la extinción de especies silvestres y daños irreversibles a los ecosistemas. Igual que a nivel planetario, en Honduras se ha buscado respuestas por medio de políticas públicas traducidas en una proliferación de normas jurídicas y una institucionalidad destinada a enfrentar la problemática ambiental.

2.- Junto a la Comisión Nacional de Medio Ambiente, creada a principios de los años noventa, y su evolución a Secretaría del Ambiente como autoridad responsable de la gestión ambiental en el país en coordinación con otras instituciones públicas que administran recursos naturales, se emiten leyes ambientales nacionales y se aprueban diversos tratados internacionales sobre este tema o los recursos naturales. Esta es la respuesta legal e institucional del Estado hondureño a los retos que representan problemas ambientales como la degradación de los recursos forestales y la biodiversidad, uso y degradación de los suelos, contaminación y manejo del agua, contaminación del aire, generación de basuras en las municipalidades y vulnerabilidad a desastres y fenómenos naturales, identificados en estudios o diagnósticos especializados. En la práctica estos problemas siguen vigentes y posiblemente en algunos casos se han agudizado.

3.- La respuesta del Derecho a la problemática ambiental en Honduras ha sido contundente. La aprobación de más de 50 convenios o tratados internacionales y más de 100 leyes secundarias sobre ambiente o recursos naturales, sumado a una cantidad indeterminada de normas reglamentarias, se presenta como un escenario jurídico adecuado, pero tiene sus inconvenientes: la cantidad y dispersión de normas legales, en un marco administrativo y judicial débil y profesionales con poco conocimiento en la temática ambiental puede ser una fórmula para la ineficacia, anulando en buena medida los impactos positivos para el ambiente que se pretende con esa normativa especializada.

4.- Pese a los obstáculos o amenazas que representa el exceso de normas legales y su desconocimiento por un buen porcentaje de actores responsables de su aplicación o 
cumplimiento, entre ellos los profesionales del Derecho, se pueden percibir oportunidades tanto para asegurar que haya una mejor tutela de los valores ambientales, como para un crecimiento personal y/o profesional de los actores involucrados. La formación ambiental en general y la jurídica en particular, es una asignatura pendiente que se deberá atender de manera adecuada y responsable en los próximos años si se pretende contribuir al desarrollo sostenible del país y la formación integral del profesional universitario.

\section{B. ¿Qué se puede hacer?}

1.- Una primera reflexión es que la academia en su especial campo de acción, debe asumir un compromiso para participar en la búsqueda e implementación de soluciones ante la problemática ambiental del país. La universidad puede participar en proyectos ambientales y la sociedad necesita de expertos en estos campos. Una planificación estratégica universitaria que incluya la investigación e innovación en temas de ambiente, además de ser una contribución para la agenda ambiental del país puede ser una opción para movilizar recursos para mejorar su gestión en general, beneficiándose también de la imagen que representa la responsabilidad ambiental, sobre todo en una época en que las carreras tradicionales han entrado en crisis.

2.- La cantidad y dispersión de normas legales es un problema que puede enfrentarse con programas de capacitación donde la academia puede hacer alianzas con las instituciones públicos o la sociedad civil que requiere estos servicios profesionales especializados. Un ejemplo de lo anterior son los diplomados para formar prestadores de servicios ambientales y en otras áreas ambientales que ya se están sirviendo en algunas universidades del país. En su mayoría estos eventos tienen un enfoque multidisciplinario.

3.- Los abogados, sean fiscales, jueces, funcionarios, procuradores o consultores ambientales deben ser capaces de comprender el andamiaje normativo en esta materia. En el campo exclusivo del Derecho es válido pensar en un programa para formar profesionales capaces de interpretar las disposiciones jurídicas que regulan el ambiente, los recursos naturales (suelos, aguas, bosques, biodiversidad, áreas protegidas, minerales e hidrocarburos, etc.) y elementos ambientales distintos (atmósfera, turismo, patrimonio nacional y educación ambiental, entre otros). Lo anterior requiere de pensar es niveles especiales (orientación o postgrado en Derecho Ambiental) donde se conjuguen los aspectos técnicos y jurídicos tanto en la teoría como en la práctica. De esta manera, además de formar profesionales en campos de moderna aceptación, la academia estará contribuyendo a mejorar las posibilidades de gestión ambiental estatal y privada. 
4.- Como plataforma de información para los profesionales del ramo, la Revista de Derecho debería abrirse a la discusión de la temática del Derecho Ambiental. Cuestionar sobre el papel de los profesionales del Derecho en el contexto ambiental, debatir sobre las propuestas de ley que inciden sobre esta materia o elaborar artículos sobre los temas ambientales desde la perspectiva del Derecho son solo algunas cuestiones que reclaman la atención de los juristas del nuevo milenio. Como canal de información la Revista de Derecho debe procurar trascender el debate académico y buscar influir sobre las decisiones políticas sobre una materia que afecta a toda la sociedad.

\section{BIBLIOGRAFÍA}

- COHDEFOR/GTZ 1996. Análisis del Subsector Forestal de Honduras. Corporación Hondureña de Desarrollo Forestal/Cooperación Hondureño-Alemana. Graficentro Editores, Tegucigalpa.

- EDITORIAL CIENTÍFICA. 1997, Diccionario Práctico de Términos Forestales y Ecológicos. Tomo II (segunda reimpresión). Bogotá, Colombia.

- FALCK, Mayra. 2007. Problemas Ambientales Clave: República de Honduras (Documento conceptual para el Banco Mundial).

- FAO. Portal electrónico. La Amenaza Hidrometeorológica en Honduras (contexto ambiental). http://www.fao.org/docrep/013/i1255b/i1255b01.pdf

- GIZ. 2011. Evaluación Preliminar sobre Causas de Deforestación y Degradación de Bosques en Honduras. Proyecto REDD + CCAD-GIZ-ICF-SERNA. Tegucigalpa, Honduras. Mario Vallejo Larios, consultor.

- HILLARY, (Sir) Edmund. 1985. Ecología 2000: La Faz Cambiante de la Tierra. Editorial Círculo de Lectores, Barcelona, España.

- ICEFI. 2014. Diagnóstico de la Situación Minera en Honduras 2007-2012. Instituto Centroamericano de Estudios Fiscales. Versión .pdf para sitio web.

- ICF. 2013. Anuario Estadístico Forestal 2012. Volumen 27. Unidad de Estadísticas/Centro de Información y Patrimonio Forestal (CIPF). Comayagüela, Honduras.

- MATEO, Ramón Martín. 1991. Tratado de Derecho Ambiental (Primera Edición). Tomo I. Editorial Trivium. Madrid, España.

- ONU 1992. Declaración de Río sobre Medio Ambiente y Desarrollo (Cumbre de la Tierra), celebrada en Río de Janeiro, Brasil, entre el 3 y el 14 de junio de 1992. Roma.

- PEREA VELÁSQUEZ. Francisco. Portal electrónico. Legislación Básica sobre Protección del Medio Ambiente. (https://www.regulaciones + ambientales + leyes + de + indias).

- PNUMA. 1999. Panorama General: Perspectivas del Medio Ambiente Mundial 2000. Programa de las Naciones Unidas para el Medio Ambiente. Nairobi, Kenia. 
- PNUMA. 2012. Geo5. Medio Ambiente para el Futuro que Queremos. Impreso en Panamericana Formas e Impresos, Colombia para Editora Novo Art, S.A. en Panamá.

- SERNA. 2004. Compendio de Compromisos Internacionales en Materia de Ambiente, suscritos y ratificados por la República de Honduras. (MARENASERNA). Tegucigalpa, Honduras.

- SERNA/PNUMA. 2005. Estudio del Estado y Perspectivas del Ambiente: Geo Honduras 2005. Primera Edición. Scancolor, Tegucigalpa.

- SOPTRAVI 1996. Guía para Investigadores de Honduras. Instituto Geográfico Nacional/ Instituto Panamericano de Geografía e Historia. Tegucigalpa.

- TARINGA. Portal electrónico. La Curiosa Teoría de Thomas Malthus. Monografía. (http:// www.taringa.net/posts/apuntes-y-monografias/5783367/La-curiosa-teoria-de-Thomas-Malthus.html)

- The Worldwatch Institute. 2012. La Situación del Mundo 2012. Hacia una Prosperidad Sostenible. (http://www.fuhem.es/ecosocial/noticias.aspx?v=9205)

- UNAH. Portal electrónico. Principios, Visión y Misión de la Universidad Nacional Autónoma de Honduras. http://www2.unah.edu.hn/?cat =1213

- USAID/MIRA 2008. Compendio Aplicado: Legislación con Enfoque en Comercio y Ambiente. Proyecto USAID/MIRA en coordinación con la Secretaría de Recursos Naturales y Ambiente. Tegucigalpa, Honduras. Mario Vallejo Larios, consultor.

- VALLEJO LARIOS, Mario. 2014. Legislación en la Gestión Ambiental de Honduras: conocimiento y Aplicación. Ediciones Guardabarranco. Tegucigalpa, Honduras.

Además, todas las normas legales mencionadas en el artículo. 